\title{
Check your GPS at the border
}

Foreign researchers working in China are falling foul of laws restricting environmental monitoring and use of Global Positioning System (GPS) equipment. Geologists, botanists, environmental scientists and meteorologists have been affected. Even those who believed that they were within the law and were collaborating with Chinese researchers have lost data, been detained and had equipment confiscated.

According to the State Bureau of Surveying and Mapping, in 2006 there were 759 cases of illegal geographical surveys and mapping, many of which involved foreigners. And there have been 20 cases of illegal meteorological surveys by foreigners since 2000. Last year, two new stricter laws governing data collection were introduced to "protect national security": these were Measures for the Administration of Foreign-related Meteorological Sounding and Information, introduced in January; and Measures Governing the Surveying and Mapping in China by Foreign Organizations or Individuals, in March. The new laws require projects to be approved by the China Meteorological Administration or the State Bureau of Surveying and Mapping, in addition to the current approval processes, and stipulate that any data are gathered and interpreted jointly with Chinese counterparts.

Some experts believe that the stricter meteorological laws were introduced in reaction to a presentation of environmental data at a conference in Hong Kong in May 2006 that, according to the official Chinese press, "amplified China's environmental problems to draw more attention to their research, heedless

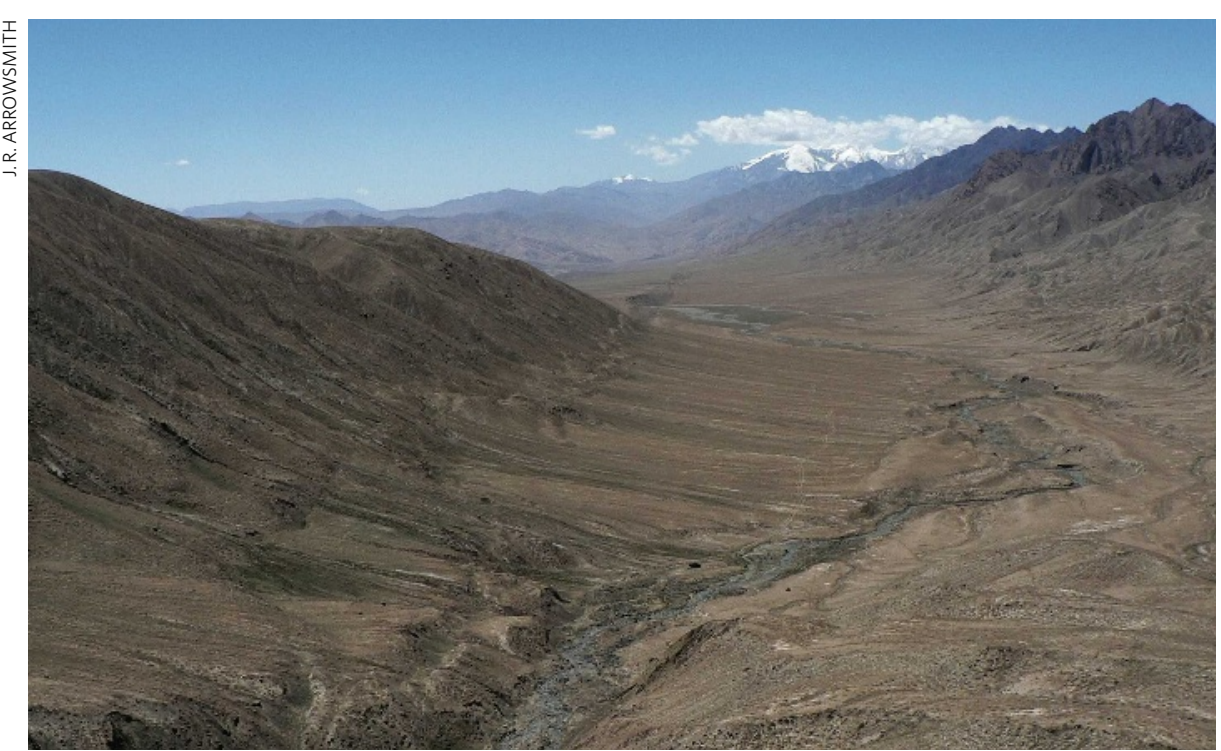

China is clamping down on unauthorized use of GPS and meteorological surveying tools by foreigners. to the fact that data collected in polluted areas doesn't represent the norm in China". The research had been carried out in collaboration with Chinese scientists, but Chinese officials say that the research was published "unilaterally", in violation of a previously agreed arrangement.

But the laws are not well known in China or at the University of Hawaii, and his collaborator Jianchu $\mathrm{Xu}$, of the Kunming Institute of Botany in Yunnan province, were stunned when in February 2007, local security officers dismantled their field stations in southwestern Yunnan province. The scientists were comparing field data with Landsat satellite data, in a project to assess the impact of rubber-tree monocultures on hydrology and land cover.

Some equipment was returned a week later, but many of the cables had been cut and underground soil-moisture sensors were lost, resulting in damage worth more than US $\$ 20,000$ and curtailing the study halfway through. "We were just starting to get very good data," says Fox. "It was just a bad experience."

Ramón Arrowsmith, a geologist at Arizona State University in Tempe, was similarly disturbed when local officials came to his team's hotel by the Altyn Tagh fault, near the border between the Tibet and Xinjiang autonomous regions in western China in March 2007. With Chinese counterparts, Arrowsmith was studying the record of deformity - ridges and humps - along the fault line to understand the history of the Indo-Asian plate collision. The officials abroad. Jefferson Fox of the East-West Center objected to his use of GPS equipment, the kind, Arrowsmith says, that can be purchased cheaply at a camping-equipment store.

Arrowsmith tried unsuccessfully to convince the officials that he was only measuring specific geological features relative to each other, not absolute topography. "It was scientifically very interesting, but from a general perspective, this was a really boring project," he says. Despite having received permission to do research through his visa application and from the local nature reserve, Arrowsmith and his team were detained in their hotel for 10 days before being allowed to leave China. "They were not abusive, but it was stressful," he says. "We're not used to being questioned."

The Chinese official media has reported copious other transgressors over the past year, including several Japanese groups. The meteorological administration says that there have been more than $\mathbf{4 0}$ such cases involving foreigners. Some of them lost equipment or faced fines ranging up to 80,000 yuan (US $\$ 11,000$ ). The UK Royal Yachting Association, preparing for the Olympics, is still trying to engineer the return of its $\notin 8,000$ (US\$16,000) meteorological station, which the Chinese government seized in late 2006. Sometimes, as in Arrowsmith's case, the penalty fell on the Chinese collaborator, who received a fine. Others contacted by Nature did not want to discuss their situation lest it affect the fate of future applications to do research in China.

The new laws require long, detailed demonstrations of an 'equitable partnership' in which data will be jointly gathered and interpreted with Chinese researchers. The proposals must also describe why the project is in China's best interest, says $\mathrm{Xu}$, adding that some projects, such as those fully funded by a foreign agency, are unlikely to get approved. "International collaborations will definitely drop in number," he says.

The US National Science Foundation's Beijing representative William Chang says that the organization is trying to spread the word to its new grantees working in China about longer application times and higher overheads to cover a greater number of Chinese researchers. "Scientists need to be better coordinated with their Chinese colleagues and better organized."

Arrowsmith is still optimistic that his projectextension request will be approved, although he says that he may have to bring a meteorologicaladministration official with him.

David Cyranoski 